\title{
An $x$-ray microscopic study of the vasa vasorum of normal human pulmonary arteries
}

\author{
JOHNA. CLARKE \\ From the Department of Anatomy, University of Glasgow
}

The first description of the distribution of the bronchial arteries in injected specimens is attributed to Ruysch in 1721 (von Hayek, 1960).

Robertson (1929), while injecting the vasa vasorum in the ascending aorta of dogs and lambs with coloured cellulose, described, without illustration, an anastomosis between the bronchial and coronary arteries through the vasa of the pulmonary trunk, thus confirming the observations of Cruveilhier (1842) and Gross (1921).

In their monographs on the lung, Miller (1947) and von Hayek (1960) state, without further amplification, that the vasa vasorum to the pulmonary arteries arise from the bronchial arteries.

Studies on human cadaveric and necropsy pulmonary arteries, using routine histological and injection techniques, led Tobin (1960) to conclude that the mural vessels were confined to the outer third of the media, that the vasa on the pulmonary veins were richer, and that venous vasa drained into the lumen of the pulmonary vein.

This work is concerned with a study of the vasa vasorum of human pulmonary arteries, using the Coslett Nixon $x$-ray projection microscope.

\section{MATERIAL AND METHODS}

Twenty-five pairs of normal, post-mortem pulmonary arteries and their principal branches were examined, within eight hours of death, from hearts in the age group 15-80 years.

The microcirculation of the pulmonary artery wall was demonstrated by injecting micropaque within physiological pressures, the arterial side through the bronchial arteries and the venous side via the bronchial veins.

$X$-ray projection micrographs of full thickness pulmonary artery wall and $1 \mathrm{~mm}$. thick sections were taken on Ilford Contrasty Plates with an exposure time of six minutes. The microscope was operated at $15 \mathrm{kV}$ and $40 \mathrm{~mA}$, with a copper target providing the $x$-radiation.

\section{OBSERVATIONS}

From an examination of the micrographs it was concluded that the arterial distribution to the pul- monary arteries originated from terminal branches of the bronchial arteries.

It was found that the adventitial arteriolar plexus was formed by arteries, 120 to $150 \mu$ in diameter, which approached the wall of the pulmonary artery obliquely, to divide and distribute longitudinal, coiled arterioles, 60 to $100 \mu$ in diameter, in the outer layers of the adventitia (Fig. 1, A-D).

The arterial vasa in the adventitia of lobar and segmental branches of the pulmonary artery showed a characteristic sinuosity, which diminished and finally disappeared, leaving parallel, straight, adventitial arterioles, 30 to $50 \mu$ in diameter, in the walls of branches less than $1 \mathrm{~cm}$. in diameter (Fig. 2, A-D).

It was clear from the micrographs that, although arterioles 40 to $50 \mu$ in diameter penetrated the deep layers of the adventitia to bifurcate and form a secondary plexus of vessels, 10 to $20 \mu$ in diameter, in the outer third of the media in the extra-hilar part of the pulmonary arteries, the arterial network was confined to the adventitia in the remainder of the pulmonary arterial tree (Fig. 3, A-D).

The venous vasa, arising in the deep, adventitial layers of the intra-hilar branches of the pulmonary artery as vessels 25 to $30 \mu$ in diameter, and at the junction of the outer and middle thirds of the media in the extra-hilar arteries (Fig. 3, E and F), traversed the pulmonary wall to form a dense network of adventitial veins, 60 to $100 \mu$ in diameter, and become tributaries of the bronchial veins (Fig. 4, B-D).

\section{DISCUSSION}

The aim of this study was to demonstrate the mural vessels in the pulmonary arteries and their branches.

Examination of the vascular patterns in the adventitia and media showed that the venous and arterial sides of the microcirculation could be differentiated in vessels with a diameter greater than $20 \mu$. 


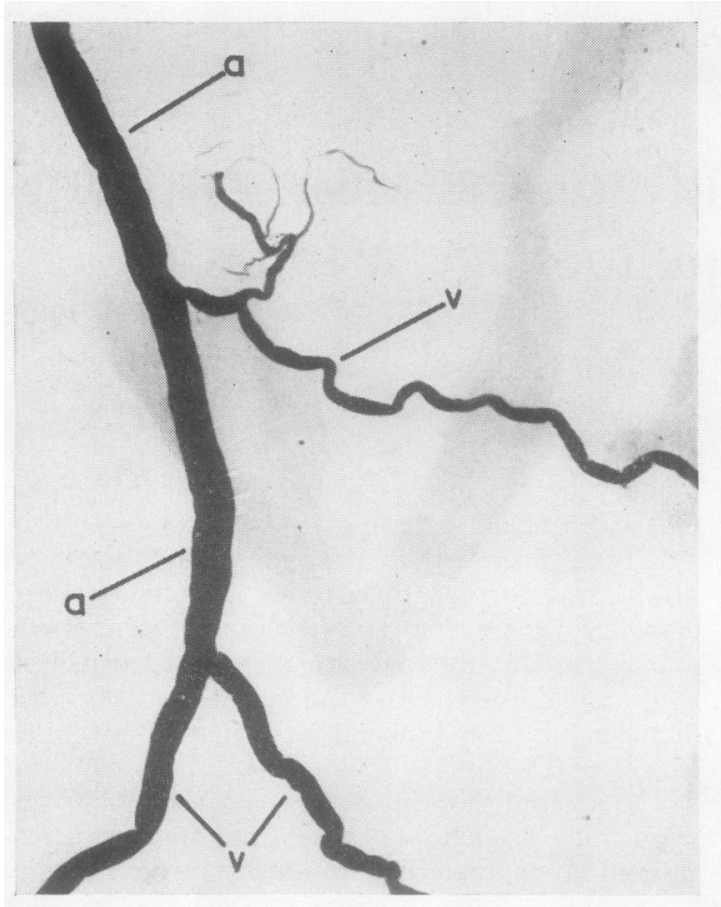

(A)

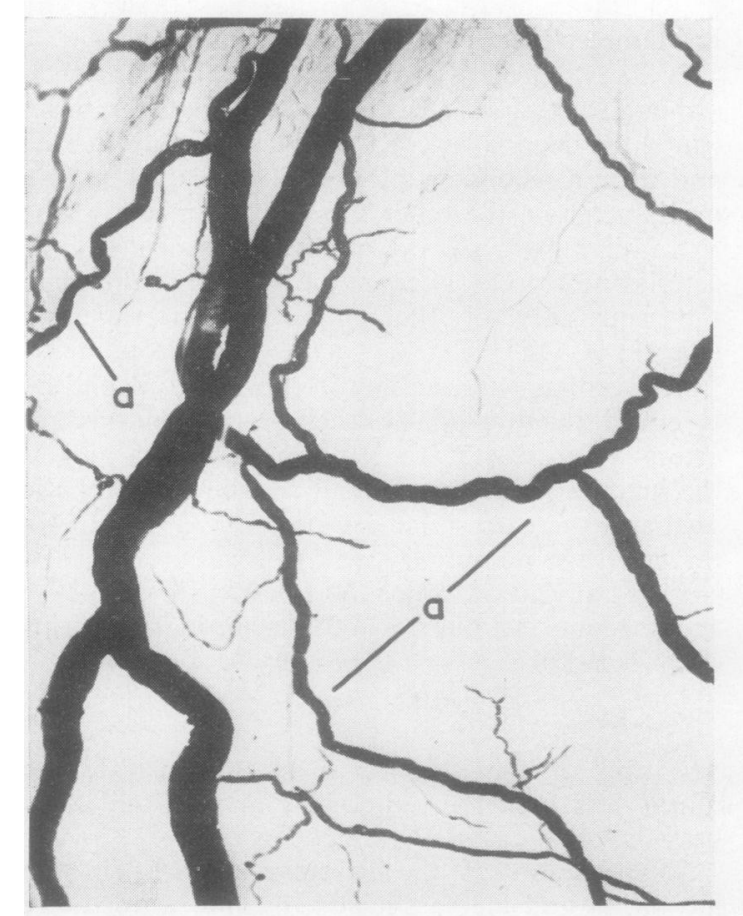

(C)

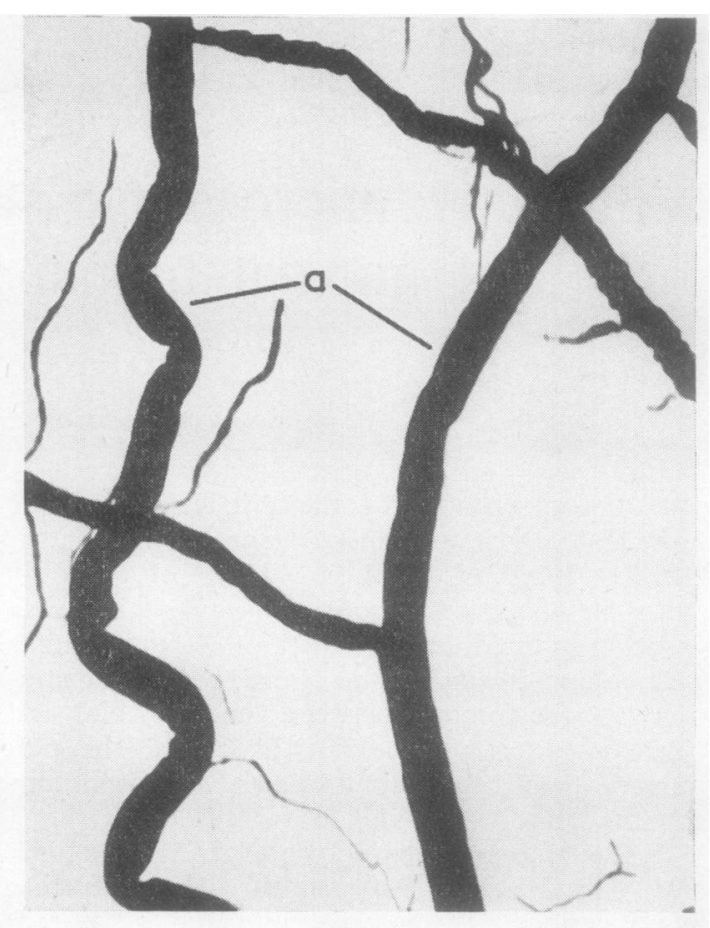

(B)

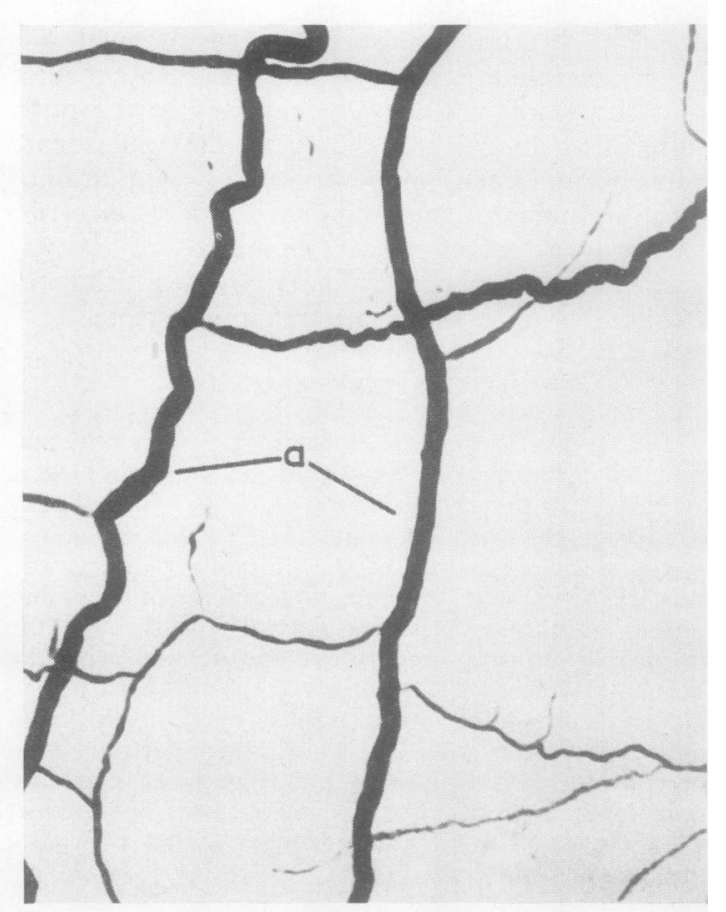

(D)

FIG. 1

For explanation of Figs. 1 to 4, see p. 566. 


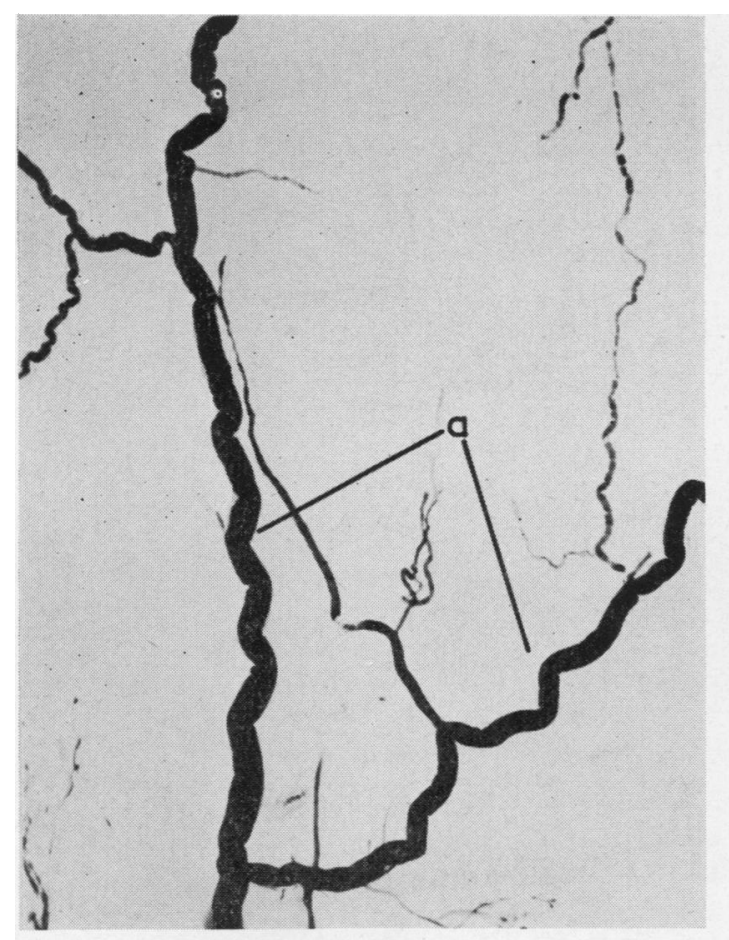

(A)

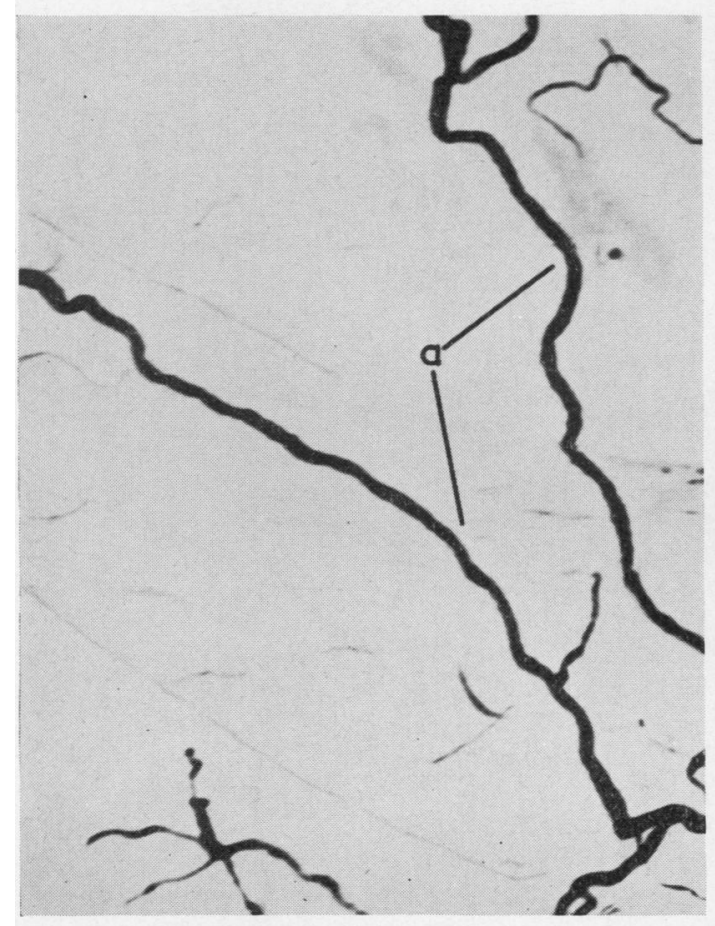

(C)

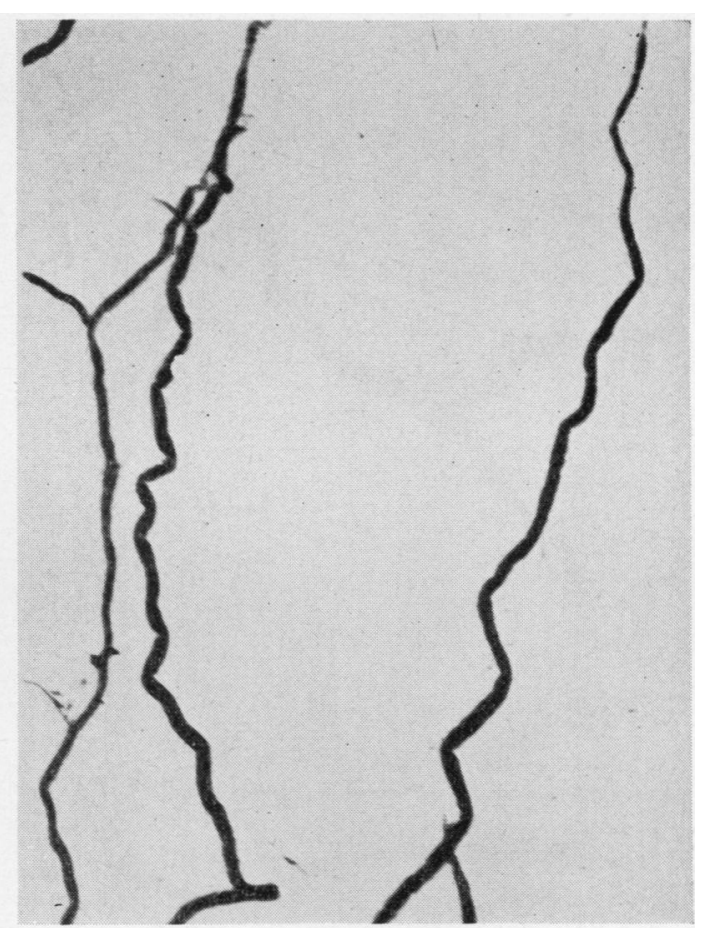

(B)

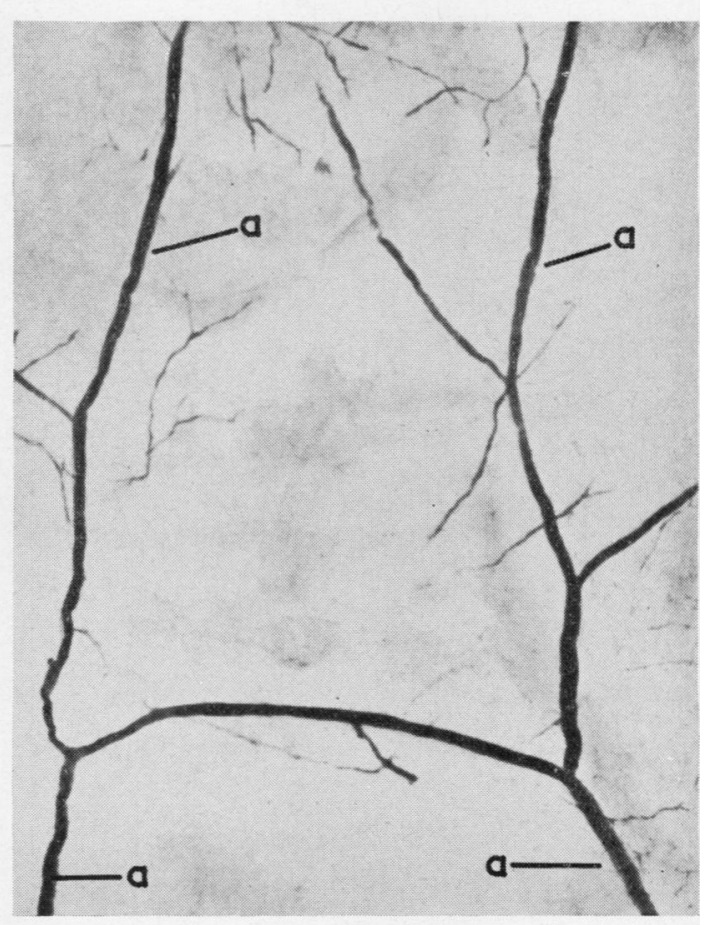

(D)

FIG. 2 


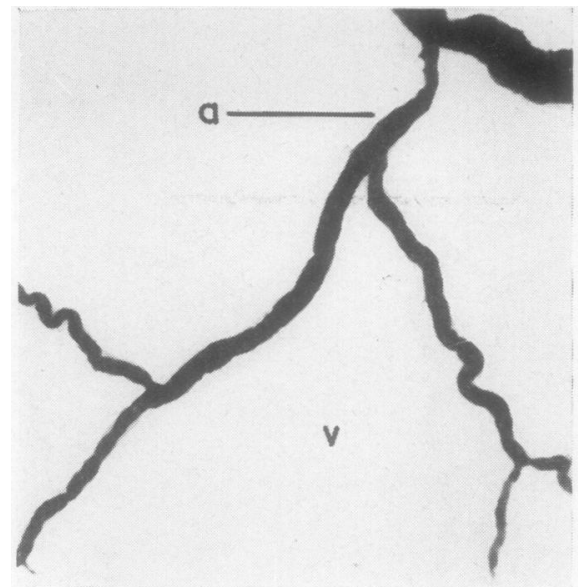

(A)

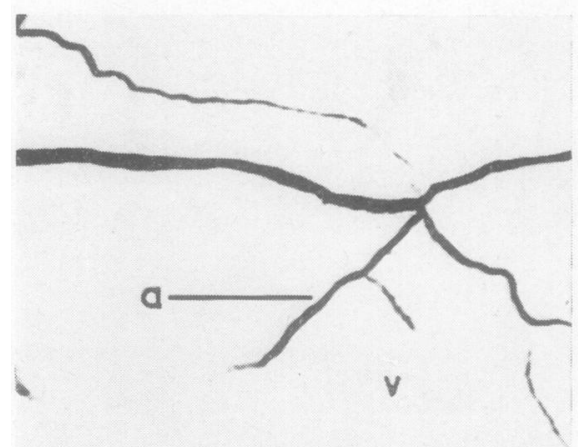

m

(C)

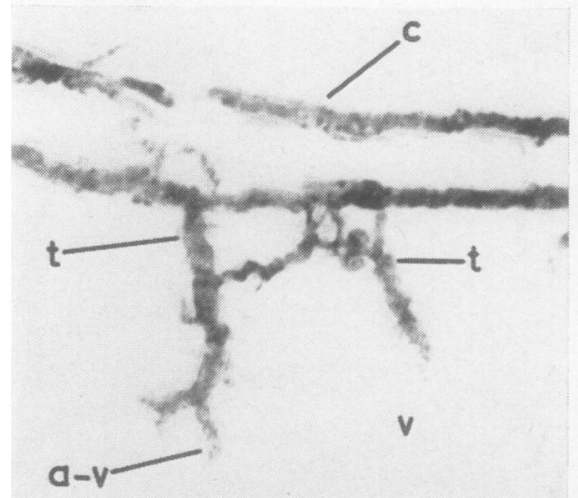

(E)

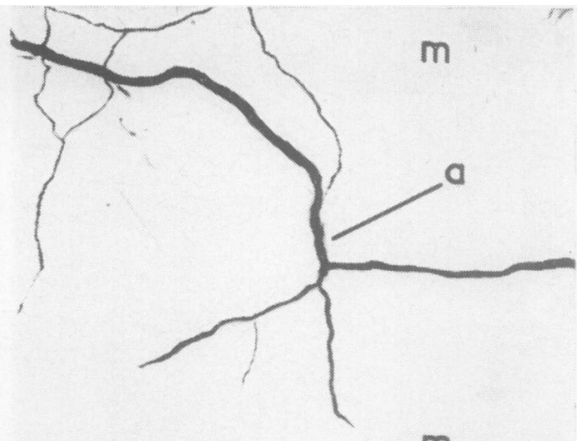

m

(B)

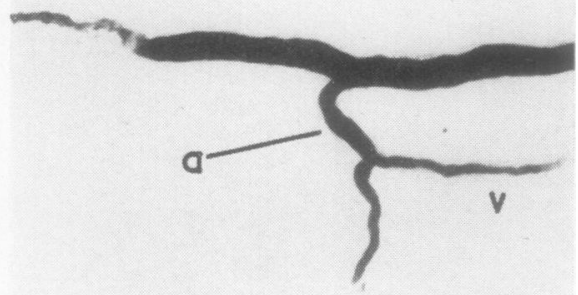

m

(D)

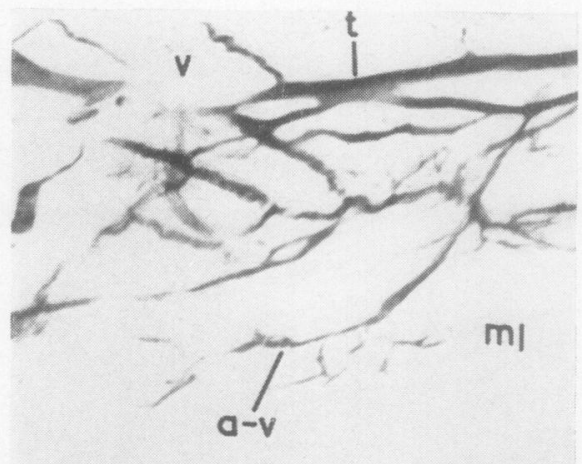

$m_{2}$

(F)

FIG. 3 


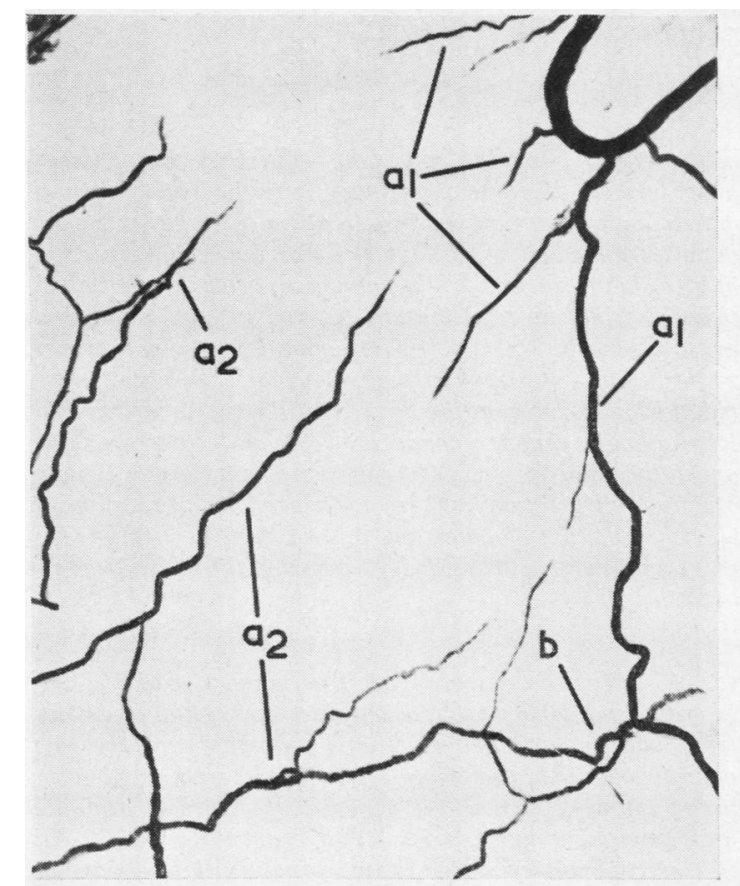

(A)

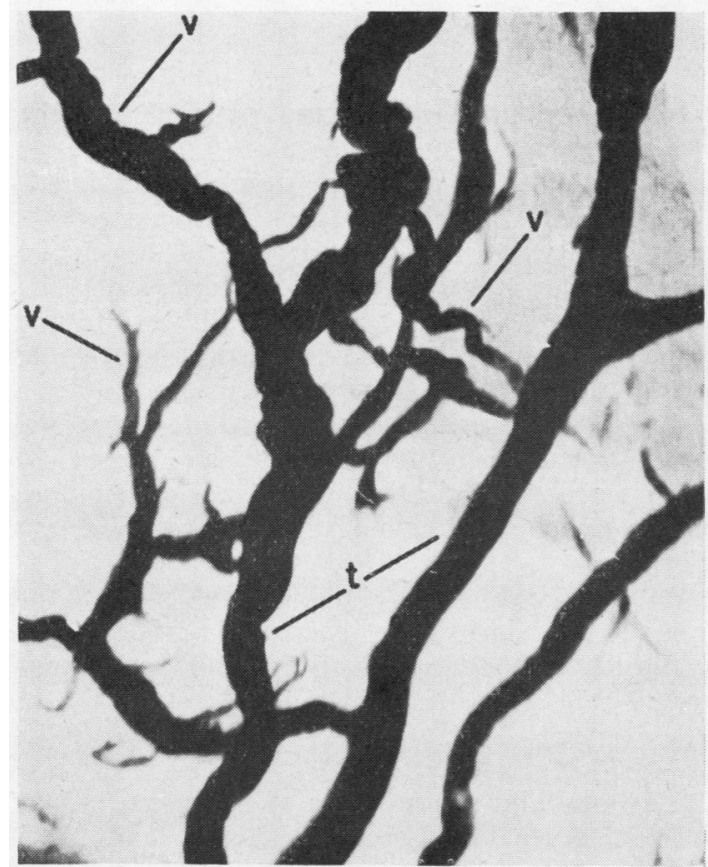

(C)

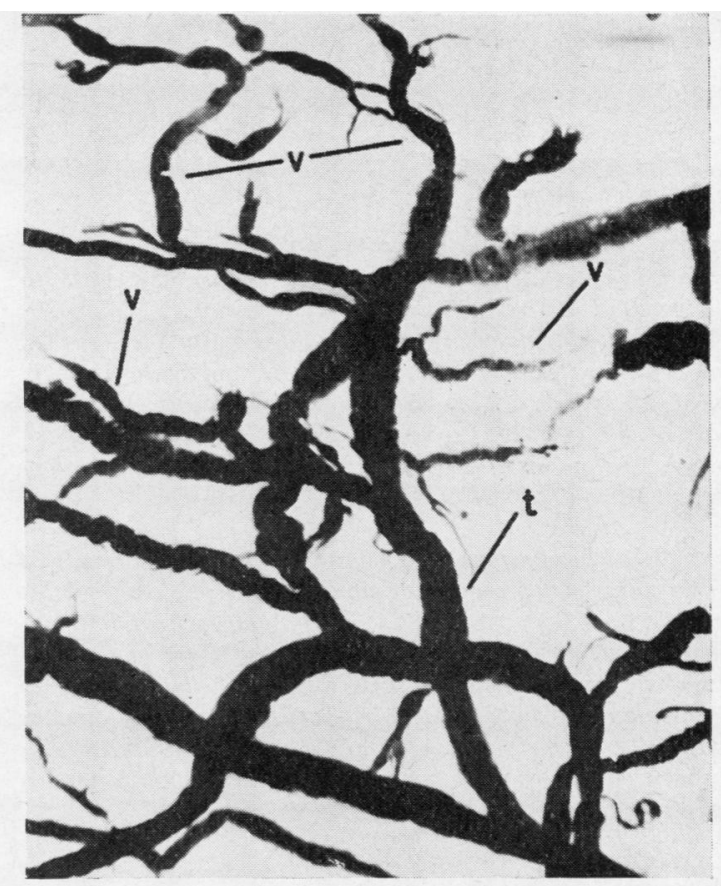

(B)

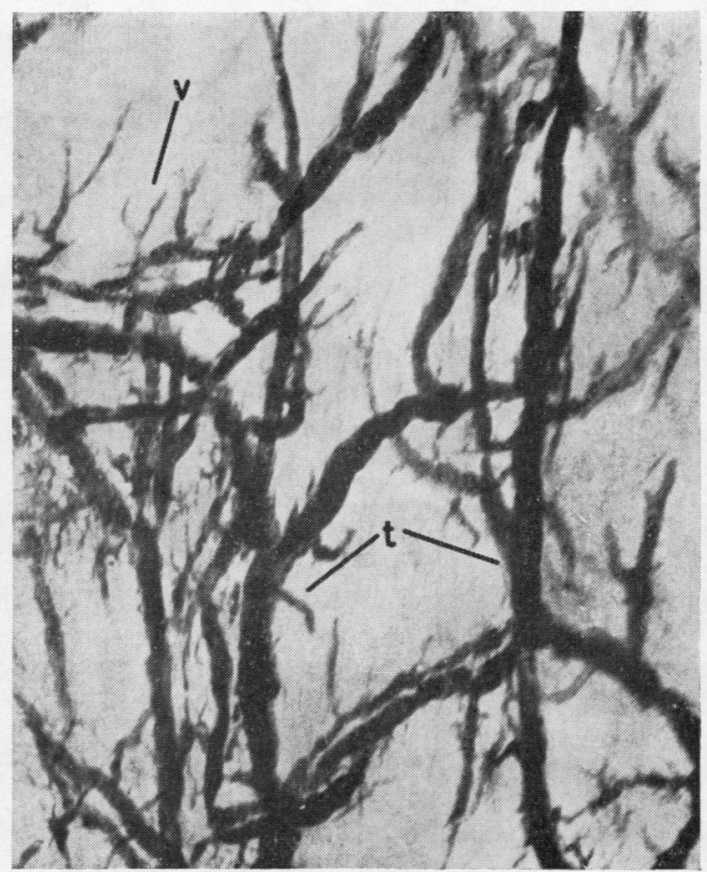

(D)

FIG. 4 
Figures 1 to 4

All micrographs except Fig. 3, A-F, are of full thickness pulmonary artery.

FIG. 1. Micrographs of (A) vight pulmonary artery showing arteriole (a) approaching pulmonary wall to divide and distribute adventitial arterioles (v), $\times 30$; (B) right pulmonary artery, showing longitudinal, coiled, adventitial arterioles $(a), \times 45 ;(C)$ left pulmonary artery, aged 65 years. Note coiling of adventitial arterioles (a), $\times 45 ;(D)$ extra-hilar branch of left pulmonary artery. Note parallel adventitial arterioles with coiling (a), $\times 30$.

FIG. 2. Micrographs of $(A)$ large intra-hilar branch of right pulmonary artery. Note coiling of adventitial arterioles still present $(a), \times 60 ;(B)$ segmental branch of left pulmonary artery. Note reduction in vasculature and diminished coiling of adventitial arterioles $(a), \times 60 ;(C)$ small intra-hilar branch of left pulmonary artery. Note sinuous adventitial arterioles $(a), \times 50 ;(D)$ terminal intra-hilar branch of right pulmonary artery. Note straight, uncoiled adventitial arterioles $(a), \times 50$.

FIG. 3. Micrographs of $(A) 1 \mathrm{~mm}$. longitudinal section of right pulmonary artery. Note arteriole (a) penetrating adventitia (v) to supply outer third of media, $\times 50$; (B) $1 \mathrm{~mm}$. longitudinal section of left pulmonary artery. Note terminal arteriolar distribution (a) in outer third of

The coiling and sinuosity of the adventitial arterioles in the pulmonary arteries and their segmental branches was interpreted as a defence mechanism against vasal stretch during systole.

It was clear from the micrographs that mural vessels were absent from branches of the pulmonary artery with a diameter less than $1 \mathrm{~mm}$., nourishment of the wall being completely luminal.

Particular attention was paid to the arteriovenous anastomoses. It was evident from the micrographs that vessels 25 to $30 \mu$ in diameter lay at the junction of the outer and middle thirds of the media in the extra-hilar parts of the pulmonary arteries, and in the deep adventitial layers in the remainder of the pulmonary arterial tree. These vessels were only found after the venous side of the microsirculation had been injected. Since an arteriolar plexus could be demonstrated in the outer third of the media of the pulmonary artery, and superficially in the adventitia of arteries within the lung, it was concluded that the arteriovenous anastomoses in the extra-hilar part of the pulmonary artery was at the junction of the outer and middle thirds of the media and in deep layers of the adventitia in its intra-hilar branches (Fig. 3, E-F). media (m), $\times 50 ;(C) 1 \mathrm{~mm}$. longitudinal section of intrahilar branch of right pulmonary artery. Note terminal arteriolar distribution (a) in adventitia (v), and avascular outer third media $(\mathrm{m}), \times 50 ;(D) 1 \mathrm{~mm}$. longitudinal section of intra-hilar branch of right pulmonary artery. Note reduction in arteriolar distribution (a) to adventitia (v) and avascular media $(m), \times 50 ;(E) 1 \mathrm{~mm}$. longitudinal section of intra-hilar branch of left pulmonary artery. Note venous tributaries $(t)$ originating in adventitia (v) to drain into longitudinal venous channels $(c)$, and arteriovenous anastomoses $(a-v), \times 80 ;(F)$ right pulmonary artery, $1 \mathrm{~mm}$. longitudinal section. Note arteriovenous anastomoses $(a-v)$ at junction of outer and middle third of media $\left(m_{1}\right.$ : $\left.m_{2}\right)$, and venous tributaries $(t)$ traversing the adventitia $(v)$, $\times 50$.

FIG. 4. Micrographs of $(A)$ left pulmonary artery $1 \mathrm{~cm}$. lateral to pulmonary bifurcation. Note adventitial arterioles from pulmonary trunk $\left(a_{1}\right)$, and pulmonary artery $\left(a_{2}\right)$ approaching and arborizing $(b) . \times 20 ;(B)$ right pulmonary artery showing adventitial network of veins (v) draining into longitudinal tributaries $(t)$ of bronchial veins, $\times 40$; (C) left pulmonary artery, showing adventitial network of veins ( $v$ ) draining into longitudinal tributaries $(t)$ of bronchial veins, $\times 45 ;(D)$ intra-hilar branch of left pulmonary artery, showing adventitial veins $(v)$ draining into longitudinal venous trunks $(t), \times 50$.

In this work the intima and remainder of the media was found to be avascular.

From studies on the blood supply to the heart, Gross (1921) concluded that an anastomosis existed between the coronary and bronchial arteries near the pulmonary bifurcation. The terminal distribution of the arterial vasa to the pulmonary trunk has been shown to occur $1 \mathrm{~cm}$. lateral to the pulmonary bifurcation (Clarke, 1964). In this series it was concluded that the arterial vasa from the coronary and bronchial arteries arborized closely but did not anastomose on the proximal $1 \mathrm{~cm}$. of the pulmonary artery (Fig. 4A).

With age, while there was no evidence of increased vascularity, an increased coiling and tortuosity of the arterial vasa could be demonstrated (Fig. 1C).

\section{SUMMARY}

The arterial and venous sides of the microcirculation in normal pulmonary arteries and their branches have been demonstrated.

The arterial vasa originate from the bronchial arteries, to be distributed in the adventitia and outer third of the media of the extra-hilar part 
of the pulmonary artery, and in the adventitia of arteries within the lung.

The veins originate at the junction of the outer and middle thirds of the media in the extra-hilar part of the pulmonary artery and in the deep layers of the adventitia in its intra-hilar branches.

The arteriovenous anastomosis occurs at the junction of the outer and middle thirds of the media in the extra-hilar part of the pulmonary artery and in the deep layers of the adventitia of arteries within the lung.

The intima and the remainder of the media was found to be avascular.

I am grateful to Professor G. M. Wyburn for his interest in this study.

I am indebted to Professor D. F. Cappell, Pathology Department, Glasgow University, and Dr. R. I.
Shaw Dunn, Pathology Department, Law Hospital, whose co-operation enabled this work to be carried out.

I am indebted to the Medical Research Council, whose aid enabled the purchase of the $x$-ray microscope.

\section{REFERENCES}

Clarke, J. A. (1964). An X-ray microscopic study of the vasa vasorum of the normal human pulmonary trunk. Acta anat., In the press. Cruveilhier, J. (1842). Descriptive Anatomy, trans. W. H. Madden, Vol. 2, p. 670. (The Library of Medicine, ed. A. Tweedie, Vol. 8.) Whittaker, London.

Gross, L. (1921). The Blood Supply the Heart in its Anatomical and Clinical Aspects. Hoeber, New York.

von Hayek, H. (1960). The Human Lung, p. 282, Hafner, New York. Miller, W.S. (1947). The Lung, 2nd ed., p. 88 . Thomas, Springfield, Ill. Robertson, H. F. (1929). Vascularisation of the thoracic aorta. Arch. Path. 8,881 .

Tobin, C. E. (1960). Some observations concerning the pulmonic vasa vasorum. Surg. Gynec. Obstet., 111, 297. 